\title{
1019 DO YOU REALLY NEED LIGHTS FOR VEHICLES
}

A G Hemasiri, J Edirisinghe* Correspondence to Department of Civil Engineering, University of Peradeniya, Peradeniya 20400, Sri Lanka

\subsection{6/ip.2010.029215.1019}

Road worthy vehicles can reduce accidents and congestion in great numbers. Lack of law enforcement contributes significantly to enter many bad vehicles to roads. This photo is a good example on how much bad vehicles without lights, number plates etc. enter to roads. 